\title{
An intelligent case-based supplier selection framework: customer knowledge management perspective
}

\begin{abstract}
In any customer driven supply chain, the acquisition of customer knowledge can help companies to attain a competitive advantage in product innovation. Since the existing approaches have not considered this knowledge as a weighted factor in the case based supplier selection processes, this paper aims to present an agent-based framework for supplier selection based on the case-based reasoning approach. This framework uses customer knowledge to evaluate the price, volume, quality grade, and delivery date of supply materials and provide them with alternative products which are closest to their first order if it was out of stock. Based on the proposed framework, a numerical example of the known case study is illustrated for highlighting the effectiveness of the approach.
\end{abstract}

Keyword: Supplier selection; Intelligent agent; Customer knowledge management; Case based reasoning 